\title{
ANALYSIS OF THE RESPONSIVE ASPECTS OF THE TRADITIONAL PERSIAN HOUSE
}

\author{
Maryam Gharavi ALKHANSARI \\ School of Architecture, College of Fine Arts, University of Tehran, \\ Enghelab Avenue, 14174-66191 Tehran-Iran \\ E-mail:mgharavi@ut.ac.ir
}

Received 4 June 2014; accepted 26 October 2015

\begin{abstract}
The traditional Persian house is a representative of the culture, way of life, and beliefs of the Persian people during the golden era of Persian civilization in 17th to early 20th centuries. The goal of this paper is to analyze the responsive features of this traditional house in order to provide a more organized recognition of this structure and its fundamental principles. It seems that appreciation of such key principles may help to exit the current confusion in understanding cultural-spatial qualities in contemporary Iranian housing.

In this regard, the paper will introduce the traditional Persian house, and will analyze its different aspects by using the seven criteria of Ian Bentley et al. in the book Responsive Environments (1985). This book speaks of broad, but somewhat universal concepts that can be applied across a wide range of areas such as old environments. This approach can be applied to reconsider the values of traditional environments. The criteria proposed are 'permeability', 'variety', 'legibility', 'robustness', 'visual appropriateness', 'richness' and 'personalization. This paper's analysis will be performed from three main viewpoints: functional-constructional, environmental, and social-cultural.

The paper discussions show that the responsiveness criteria are achieved in the traditional Persian house. It seems this achievement results from intelligent application of fundamental, structural principles of the traditional Persian house that provides suitable ground for answering functional-constructional, environmental and social-cultural issues through common solutions in an integrated entity.
\end{abstract}

Keywords: traditional Persian house, Persian architecture, functional-constructional properties, environmental properties, socialcultural properties, responsive environment.

\section{Introduction}

The traditional Persian house (TPH) is known as a main representative of the golden era of traditional Persian architecture. The Iranian academic community has widely discussed and studied the values of this entity, while there is a vast negligence about it among the general community and executive authorities. Many cases of valuable traditional houses have been destroyed by private and sometimes public sections. At the same time, there have been extensive cases of construction in response to the increasing need for residential units in the great cities of Iran. Unfortunately, these kinds of constructions do not respect cultural values and there is a general confusion in describing and reproducing cultural qualities in contemporary Iranian housing, although more recently, tendencies and attentions toward traditional patterns can be observed in the construction of some Iranian houses. In this regard, the present paper tries to extract the fundamental principles that shape the TPH. Revitalizing these principles can help the traditional values reemerged alongside the architectural expressions which belong to the present time.

Although the TPHs have existed since millennia ago, in this paper, the TPH mainly refers to the houses built between $17^{\text {th }}$ and early $20^{\text {th }}$ centuries, during which, they have been influenced by the Islamic Persian culture along with environmental and climatic factors. This era includes one of the golden periods of Persian architecture. The accordance of this architectural entity with the culture and lifestyle of the inhabitants, as well as the climate and environment 
has produced a high architectural quality which culminates in the Qajar dynasty era around 19th to early 20 th centuries ${ }^{1}$.

The geographical area, in which the traditional Persian housing pattern is present, is also wide. The TPH can be introduced by a group of patterns having their special properties according to every micro-climate and every regional subculture; however there are common specifications which unify these patterns. Although special properties of the TPH can be found among different cities and houses, the focus of this paper is based on the more general features and common specifications. $^{2}$

There are some considerations affecting the selection of the TPH pattern. The most important one is climatic situation. Since the main two climatic regions of Persia are hot-arid and cold areas, this paper will concentrate on the patterns generated in these two climatic regions. The second consideration is about urban situation. This paper focuses on urban dwellings as they are more affected by cultural issues. Rural dwellings which are more affected by livelihood issues are not included in this analysis.

The TPH basically has arisen from an ancient Persian viewpoint. Ancient Persians believed in the four elements of water, soil, wind and fire as the fundamental and generating elements of the cosmos. ${ }^{3}$ Because of this symbolic belief, the TPH, being one of the main products of the Persian cultural and architectural heritage, was known as an entity regulated by water, soil, wind and sun, in accordance to the spirit and body of the residents. Their beautiful roofs indicate the importance of the shelter, and also point to the heavens above. Their inward-looking aspect refers to the superiority of the individual's life and self-purification. The formation of the house patterns over time has been established by making it compatible with its environmental and cultural context and with the users' changing needs through days, seasons and passing years. So it seems that there exists an interaction of mental and physical specifications in this architecture. ${ }^{4}$

\footnotetext{
1 For more information about the historical process of Persian architecture cf. Pope 1976; Kiani 2000; Pirnia 1992.

2 This can be resembled to the Persian carpet though the Persian carpet has differences in colors and patterns which is resulted in special properties of this carpet in every region, there can be recognized a general common pattern.

3 For more information about the ancient Persian belief in this regard cf. Yarshater 1996; Ardalan, Bakhtiar 1973. This belief is somehow comparable to one of the ancient Greek's ideas about the main elements of the nature. Nature in the belief of Empedocles $(490-430 \mathrm{BC})$ is constituted of earth, air, fire and water.

4 For more information about the effect of spiritualties on Persian architecture cf. Ardalan, Bakhtiar 1973.
}

Presenting a general introduction to the qualities of the TPH, this paper aims to analyze the different aspects of this architecture. In this regard, it will focus on three main aspects which are functional-constructional appropriateness, environmental appropriateness and social-cultural appropriateness as the context of the analysis. These three aspects cover different features of an architectural entity from physical and technical to mental and human issues.

It is chosen some criteria to develop analytic view relating these aspects. In this regard, it is used criteria presented in the book 'Responsive Environments' (Bentley et al. 1985). In this book the writers pursue the idea of making good place for people. They are interested in why contemporary architecture are sometimes criticized as inhuman and repressive. So they propose a practical approach that identify architectural properties that provide the users with an essentially democratic setting, enriching their opportunities by maximizing the degree of choice available to them. They call such places responsive. So the book tries to demonstrate the specific characteristics that make for comprehensible, friendly and controllable places; as opposed to the alienating environments often imposed today (Bentley et al. 1985). It speaks of broad, but somewhat universal concepts that can be applied across a wide range of areas such as old environments. This approach can be applied to reconsider the values of traditional environment.

The responsive criteria presented in this book and are used for this analysis are 'permeability', 'variety', 'legibility', 'robustness', 'visual appropriateness', 'richness' and 'personalization'. These criteria help to link through mental ideas to the physical fabric of the built environment which is TPH in this research. Although this list is not exhaustive, but it covers the key issues in making places responsive. It seems they emphasizes on substantial users' behaviors which are not dependent to time and space limits.

The research structure is shown in Figure 1.

According to 'Responsive Environments', these criteria are described as below:

1. Permeability means the quality of design that affects where people can go and where they cannot (Bentley et al. 1985: 9).

2. Variety means the quality of design that affects the range of uses available to people (Bentley et al. 1985: 9).

3. Legibility means the quality of design that affects how easily people can understand what opportunities it offers (Bentley et al. 1985: 9).

4. Robustness means the quality of design that affects the degree to which people can use a given place for different purposes (Bentley et al. 1985: 9). 


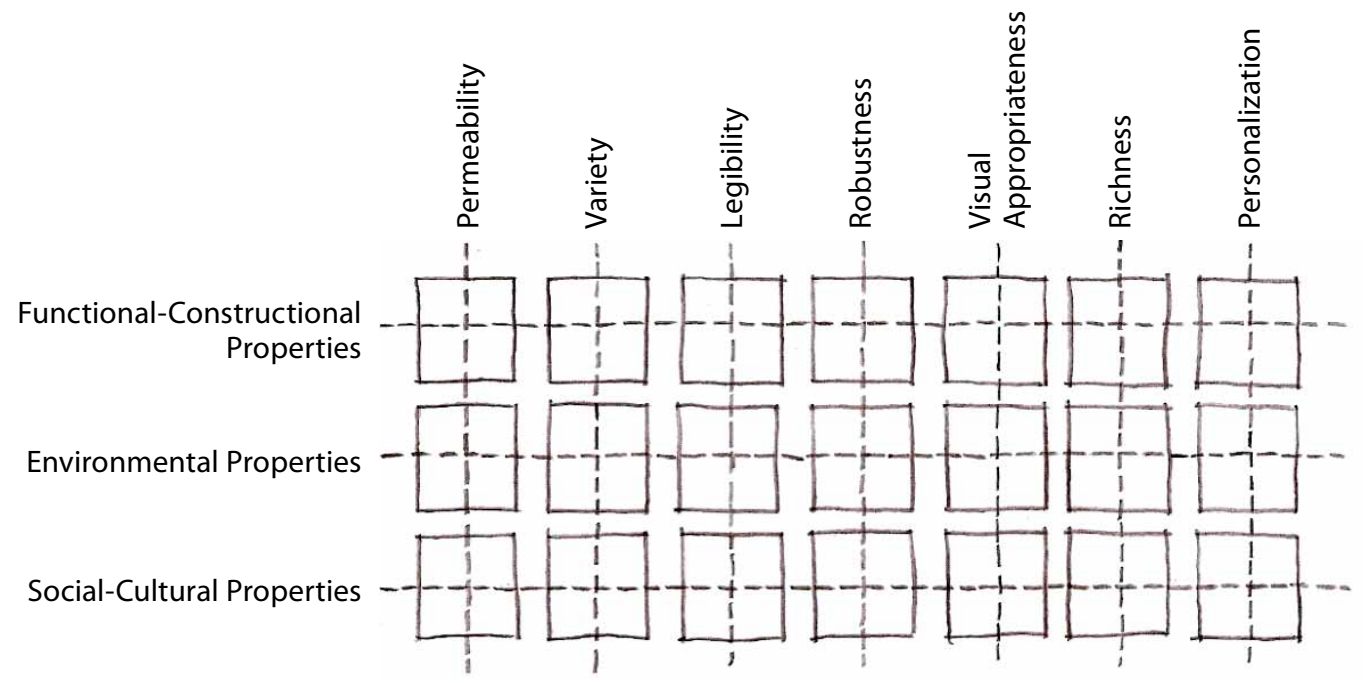

Fig. 1. The paper's structure according to functional-constructional, environmental and social-cultural properties (described in three rows) of the TPH and their analysis according to responsiveness criteria (described in seven columns)

5. Visual appropriateness means the quality of design that affects whether the detailed appearance of the place makes people aware of the choices available (Bentley et al. 1985: 9).

6. Richness means the quality of design that affects people's choice of sensory experiences (Bentley et al. 1985: 9).

7. Personalization means the quality of design that affects the extent to which people can put their own stamp on a place (Bentley et al. 1985: 9).

In the final part of each section, the quality of being responsive to these seven criteria is categorized and presented in separate tables.

\section{Background and method of the research}

The most comprehensive researches about the TPH has been done by M. K. Pirnia. ${ }^{5}$ His lectures and books provide key information about the traditional Persian architecture which also includes traditional houses. Apart from Pirnia's studies, there are books including studies on single aspects of the traditional house. There are published studies such as 'The Norm of Finding Shape in Iran's Architecture' by L. Abolghasemi (1987) or 'Urban Structure and Architecture in the Hot Arid Zone of Iran' by M. Tavassoli (2012) which discuss the climatic or constructional aspects of the traditional

\footnotetext{
5 Mohammad Karim Pirnia (1922-1997) was a researcher of the history of Persian architecture and a lecturer in the Faculty of Fine arts, University of Tehran. He was with the Antiquities Conservation Organization of Iran for several years before Iranian Revolution. His books and research works on Persian history of architecture are among the main teaching references in the faculties and departments of architecture in Iran.
}

Persian architecture. At the same time, this architecture has great potential for more future studies.

This paper tries to open a new analytical viewpoint toward the TPH. The main analysis are categorized at the end of each section of the paper in the form of a Table that extracts important points and introduces them according to responsiveness criteria. The main approach of the research is based on qualitative analysis. It tries to take advantage of basic historical, technical and analytical studies about traditional Persian architecture along with writer's observations, interviews with some of the TPH inhabitants and personal notes over several years. The inductive base of qualitative discussions of the research will be strengthened by logical argumentation. The main tactics of gathering information are observation and survey. Evidential and library-based studies are also used.

\section{Functional-constructional appropriateness of the TPH}

\section{General functional model}

Similar to other urban elements in the architecture of Persia, the courtyard plays the generic and main role in the TPH. The significant specification of the urban texture produced by the TPH and other urban functions can be recognized as a soft and flexible geometry, which is regulated around distinctive rectangular courtyards (Fig. 2a, 2b, 2c).

By surrounding the main courtyard which is the primary element of the house organization, each of the roofed spaces of the house will be situated in its specific place (Fig. 3). 


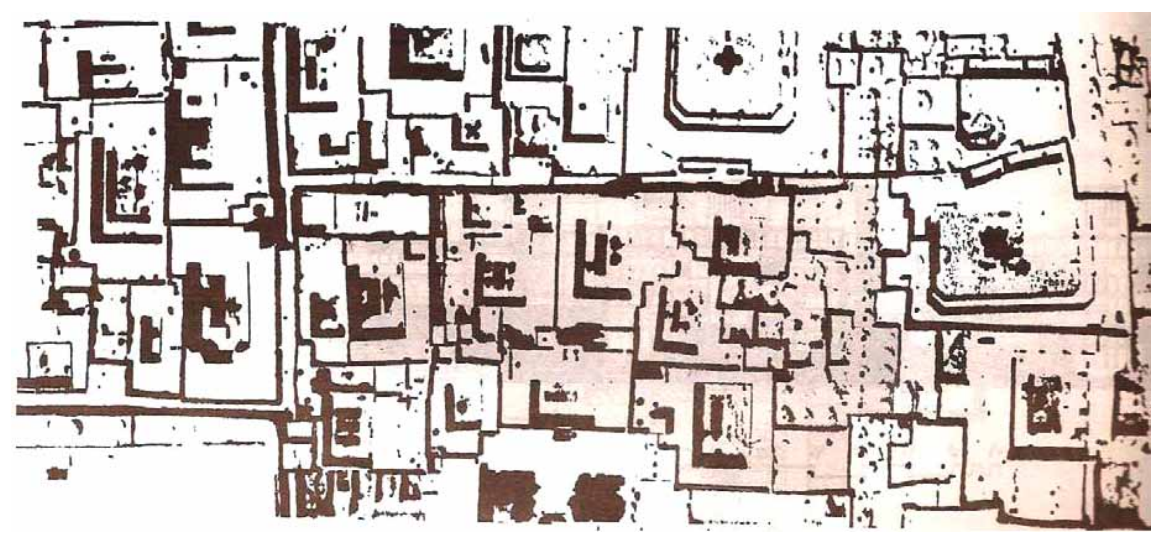

Fig. 2a. Aerial view of Mosalla neighborhood in Yazd (Ghezelbash and Abouzia 1985: 107)

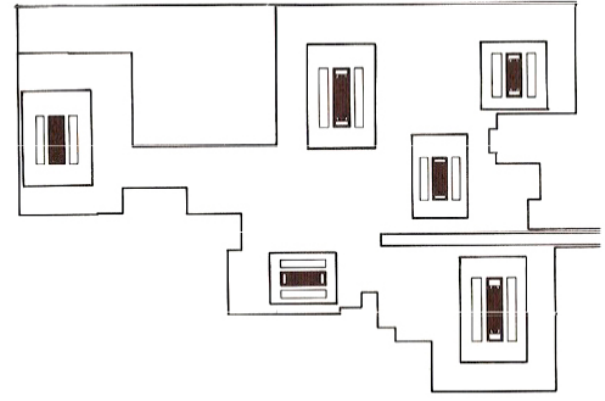

Fig. 2b. Site plan of the highlighted part of Mosalla neighborhood (Ibid., p. 32)

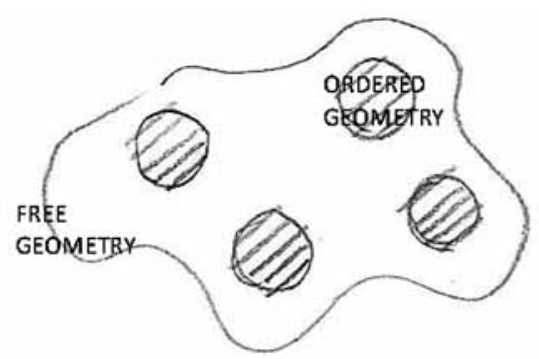

Fig. 2c. A schematic diagram results from Figures $2 a$ and $2 \mathrm{~b}$ which shows the role of courtyards as an ordered geometry in identifying free geometry of urban texture

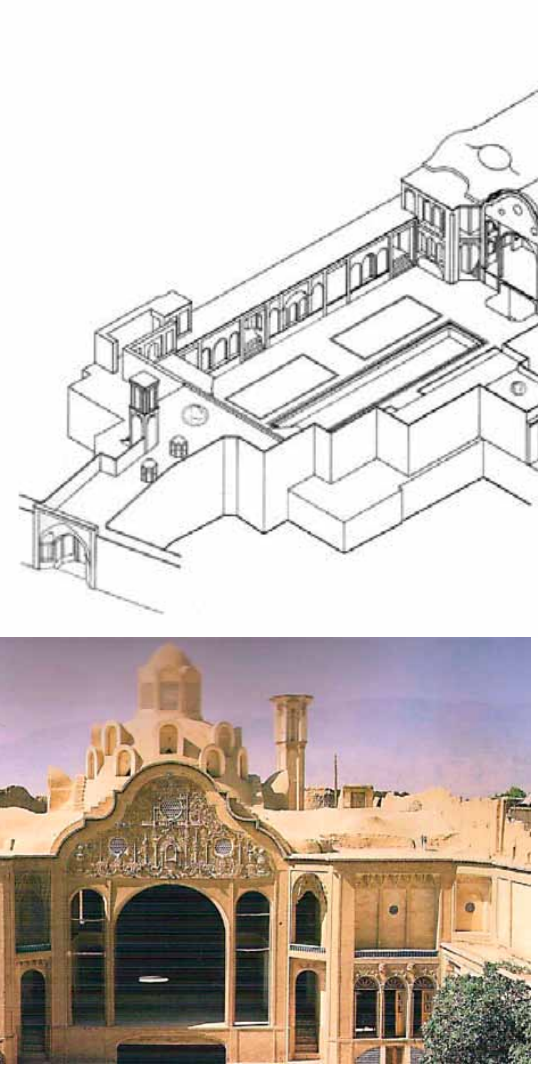

Fig. 3b. Façade of the southern 'Eivan' of Boroojerdiha House (lbid., p. 35)
Fig. 3a. An example of an advanced TPH. A general perspective of Boroojerdiha House in Kashan (Documentation and Research... 1966: 35)

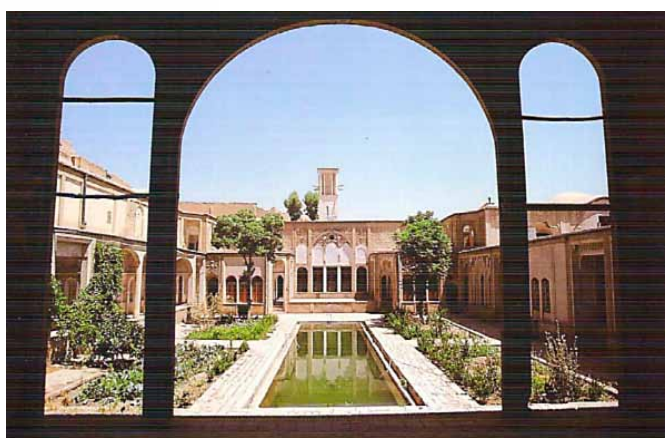

Fig. 3c. General view of the courtyard from southern 'Eivan' of Boroojerdiha House (Ibid., p. 44) 


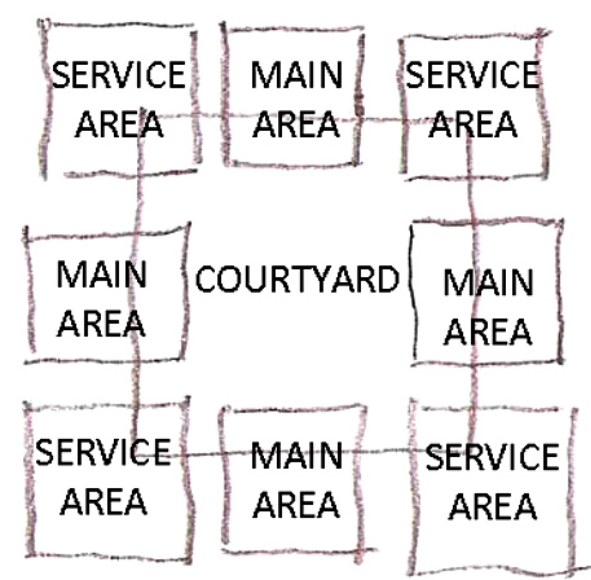

Fig. 4a. A schematic plan which shows arrangement of main areas, secondary areas and service areas in relation to the courtyard in a TPH

The horizontal section model of the Persian house comprises one or a number of rectangular courtyards that are flanked by the roofed spaces. The main spaces are located on the sides of the rectangle and the service elements are located in the corners (Fig. 4a). In the vertical section model, the main elements are raised a few steps above the courtyard level, with the secondary elements above them, while the service areas go down from the courtyard (Fig. 4b). As it will be explained in the next sections of the paper, the location of the elements and spaces in the general model is mainly based on the degree of privacy, degree of providing services, and also the climatic considerations. Similar to other urban entities in the Persian architecture, lifestyle and its functional issues play the vital role in the organization of the TPH.

\section{The components}

The Persian House comprises the elements of the central courtyard ('Hayat'), the entry (consisted of the gate ('Dargah'), vestibule ('Hashti') and corridor ('Dalan') ), the main room which has an aperture with five divisions ('Panj-dari'), a secondary room which has an aperture with three divisions ('Seh-dari'), a room with the vertical sliding sash ('Orosi'), 'Eivan', the wind tower ('Baad-geer') and its room ('Talar') ${ }^{6}$ which is usually used in warm regions, a kind of roof which is used for sleeping in warm season ('Mahtabi or 'Bahar-khab'), the corridor ('Mard-gard'), the main hall ('Takht-gah'), the pool room ('Houz-khaneh' and 'Sardab') which is usually in the basement, the corner upper room ('Bala-khaneh Gooshvar'), the storage room ('Pastoo' and 'Sandoq-khaneh') and the 'Tenabi'

\footnotetext{
6 It is mainly used in warm regions.
}

Fig. 4b. A schematic section which shows arrangement of main areas, secondary areas and service areas in relation to the courtyard in a TPH

(Fig. 5). The spaces of the Persian House have not taken shape on the basis of function. They are rather spaces with architectural definitions that can be used according to the requirements of the day or the different times of the year in various ways. These spaces and their composition are emerged according to culturalsocial issues, family relationship, life style, climatic situation, available materials, structural necessities, human scale, light, sight and landscape and functional issues during centuries.

As the main element of the spatial organization of the house around which the other elements form, the courtyard plays the role of an inward-looking garden that the spaces around it look onto. Usually an oblong rectangular pool occupies the center of the courtyard flanked by various trees and flowers. The courtyard proportion was usually based on golden proportions.

On the main side of the courtyard facing the south is placed the 'Orosi' as the primary element around the courtyard. This room has perforated windows with colored glass pieces in the perforations. The windows act as vertical sash windows. This special window gives this type of room its name. This room is usually crossshaped in the horizontal section. This horizontal shape is called 'Shekam-darideh'. The recess at the back of the 'Orosi' room (one of the arms of the cross) is called the 'Shah-neshin'. Light falling on the glass pieces combined with the view of the internal garden creates a considerable effect.

'Talar' and the wind tower are situated in the warm area on the southern side of the courtyard in front of the 'Orosi' room. 'Talar' is a space similar to an 'Eivan', which is open on the courtyard side and at the back of which is the wind tower ('Baad-geer'). 

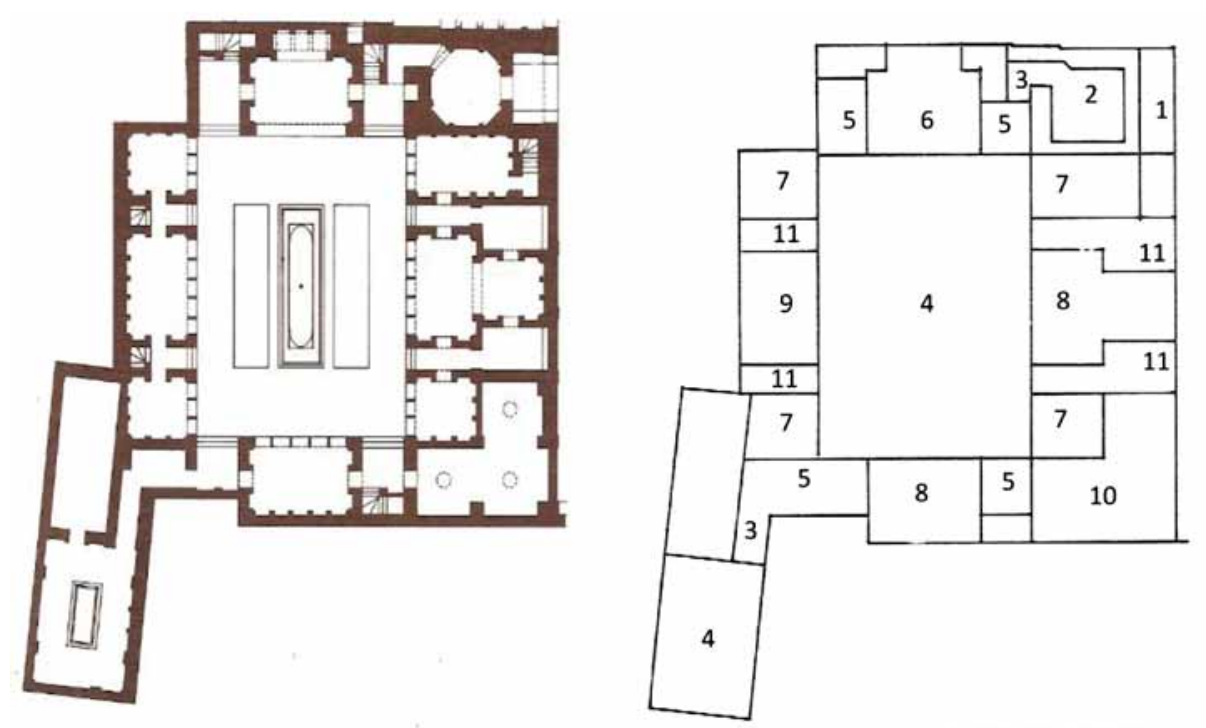

$$
\begin{aligned}
& 1 \text { - Entrance gate } \\
& 2 \text { - 'Hashti' } \\
& 3 \text { - 'Dalan' } \\
& 4 \text { - Courtyard } \\
& 5 \text { - 'Takhtgah' } \\
& 6 \text { - 'Talar' and 'Baad-geer' } \\
& 7 \text { - 'Seh-dari' room } \\
& 8 \text { - 'Panj-dari' room } \\
& 9 \text { - 'Orosi' room } \\
& 10 \text { - 'Matbakh' and water storage } \\
& 11 \text { - 'Mard-gard' }
\end{aligned}
$$

Fig. 5. Settlement of the components of a TPH in Gazorgah neighborhood in Yazd, Ghezelbash and Abouzia, 1985, p. 23.

The other rooms that surround the courtyard (on the east and west sides) usually have a 'Panj-dari' (five divisions aperture) at the center and two or more 'Sehdari's (three divisions aperture) on the side facing the courtyard. The names given to these spaces derive from the number of the glazed doors in each space that open onto the courtyard. Access to these rooms is made through covered spaces called 'Takht-gah', or corridors called 'Mard-gard'.

Above the 'Seh-dari' rooms and on the sides of the 'Orosi' or 'Panj-dari' rooms, which usually have high ceilings, two small rooms (Bala-khaneh Gooshvar) would be placed on the upper level that were used for retreat and privacy. At the rear of the main rooms were spaces called 'Pastoo' or 'Sandoq-khaneh' for storage. In the basement would be placed service spaces such as the 'Houz-khane' or more storage. Service spaces such as the entry that is comprised of vestibule ('Hashti') and a corridor ('Dalan'), the kitchen, the stables, and the WCs would be fitted in the corners. ${ }^{7}$

\section{The construction method}

The construction of the Persian House followed a process in which after an initial planning on the basis of the model outlined in the previous section and the determination of the number of the elements required and the location of each space, the dimensions and components of the spaces were determined using some measures or scales called the 'Peimoon'8. In fact choosing the 'Peimoon' was a means at the disposal of the

\footnotetext{
7 For more information about the TPH and its component cf. Ghazbanpoor 2001; Ghezelbash, Abouzia 1985; Memarian 1996; Pirnia 1991.

8 Predefined standard pattern which specifies the components' certain location, dimension and type of roof.
}

architect, by which the dimensions, proportions, and the interrelationships in a building would be organized, and a human scale instilled in it. In addition, the possibility of the prefabrication of elements such as doors and windows and even carpets to fit the floors of the spaces was provided by this regulation.

Basically, every components of the TPH have a certain location, dimension and type of roof which is defined by the triple Peimoon systems i.e. small Peimoon, big Peimoon and sub-Peimoon. ${ }^{9}$ Following the type and dimensions of each space the roof shape of the spaces would be determined too. ${ }^{10}$ Although the general pattern, the components and their composition regulation is predefined, the potent and taste of the traditional architect on one hand, and the needs of the client and existing circumstances (such as shape and dimensions of the land) on the other hand produced the diversity and individual beauty of the design. The taste and experience of the traditional architect intensify the diversity of house by designing ornaments and special details (such as locating walls and adding or subtracting some elements) that is produced by necessity.

The final designing process was done using defined masses that produced a small model of the below section of the house elements complex. After this, the plan achieved by such three dimensional approach was executed on a grid network and the construction operation has begun.

\footnotetext{
9 It can be resembled to the work of a Persian poet putting words in a poem structure ('Ozan-e-aroozi'), a Persian musician adjusting music notes in a music structure ('Dastgah-e-mosighi') or a Persian carpet designer embedding flower and bushes ('Gol-obotte') in the traditional carpet pattern.

${ }^{10}$ For more information about the traditional roofs cf. Bozorgmehri 1987; Pirnia 1991; Pirnia 1994.
} 
At this stage, the site would be excavated as necessary. This was taken advantage of in a number of ways. First of all the earth collected would be used to make clay bricks ('Khesht'), which were considered to be the primary building material. Secondly, by placing the building in the depth of earth, the lateral movement of the arced roof would be controlled; and as we will see later on, the adjustment of the temperature of the building would become considerably easier. Furthermore, this would also affect access to water and its storage.

Following excavation and plotting the plan of the building on the site, the erection of the walls would commence. In building the walls and the roof, the main material was the clay brick, while in places such as the joint between the building and the ground, or the eaves, which were subject to the adverse effects of rain, snow, or water, fired bricks would be used. One aspect of construction which was always kept in mind was that by discarding non-load bearing areas as much as possible such as perforating parts of the walls or roofs and cutting out apertures in the walls.
By this technic, the weight of the building would be reduced as much as possible. In addition to weight reduction and saving building materials, this would result in giving a rhythm to the surfaces and variety all over the building as well as engendering a human scale. As this will be mentioned in part 2.2, by casting shadows or using two separated layers in the roofs, this would also affect the adjustment of the environmental conditions. Furthermore, recesses in walls were then used as shelves.

The traditional architect has had effective presence in every stage of work and has controlled dimensions and quality of construction according to his experience. Many of the decisions about the house details or small changes in general design which would led to better proportions and more beauty had made in this stage. ${ }^{11}$

In a conclusion of part 1 , here in Table 1 is a categorized items which can imply responsiveness to functional-constructional requirements in the TPH.

Table 1. Responsiveness to functional-constructional requirements

- From outside, the structural pattern of the entrance gate draws attention and is welcoming.

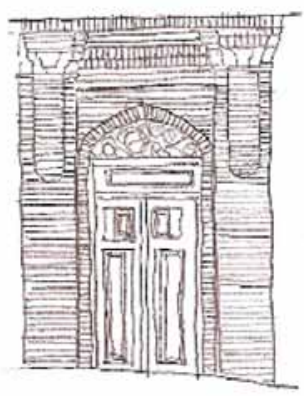

- The spatial openness of the courtyard is inviting. The entrance structure guides movement from 'Hashti' to a hierarchy of corridors ('Dalan') which lead to the courtyard.

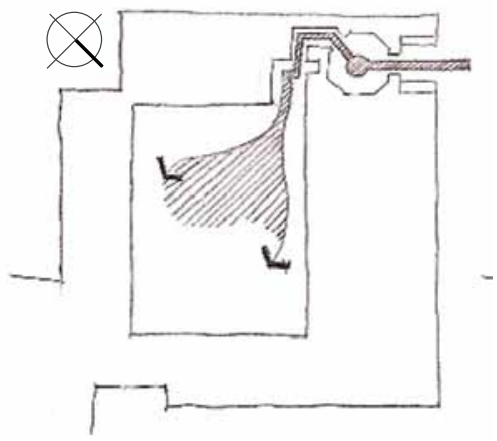

- The structural pattern of the house produces permeability from courtyard to the surrounded spaces.

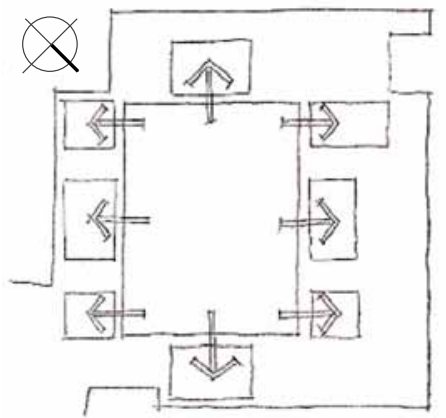

- Semi-open spaces ('Talar', 'Takht-gah', 'Mard-gard') function as articulations inviting from an open space to a closed one.

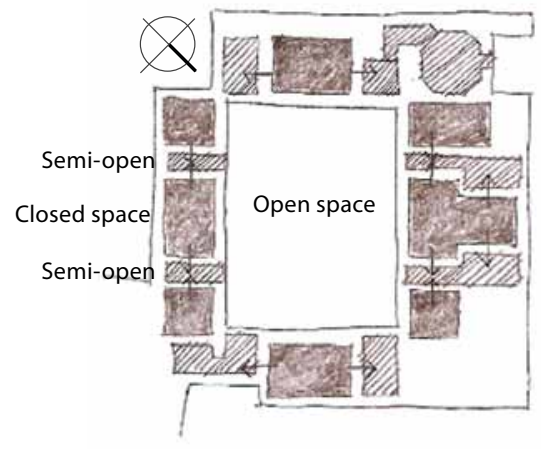

${ }^{11}$ For more information about the construction methods in the traditional Persian architecture cf. Abolghasemi 1987. 
- The variety is produced by the organization of open spaces, semi-open spaces, and closed spaces.

- The variety of different places on different levels such as 'Sardab', courtyard, 'Paeen-khaneh', 'Bala-khaneh', 'Mahtabi', 'Bahar-khab' and roof (as a functional and identified place) accommodates different functions.

- The traditional house produces diversity of scales through producing small, mid-size, and big spaces. This variety of scales provides suitable spaces for different activities.

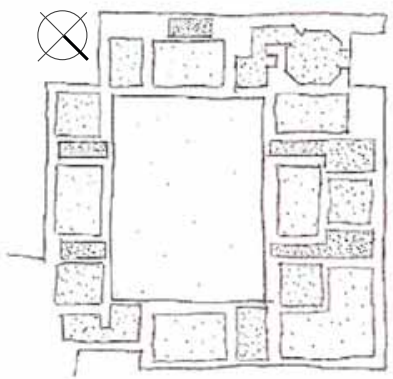

- Use of a variety of materials and processes in different locations, according to the functional-structural requirements.

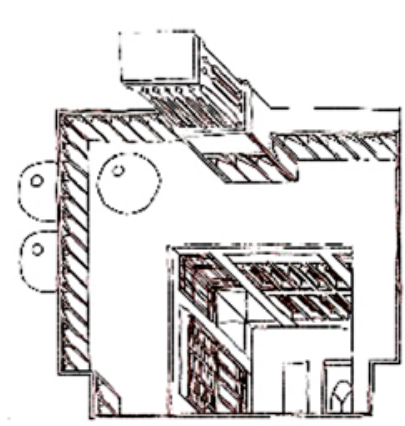

- The variety in roofing types and ceiling heights in 'Sardab', 'Shah- neshin', 'Seh-dari', 'Panj-dari', 'Orosi', 'Pastoo' and 'Eivan' creates different spatial senses. These spaces may have heights of one, two, or even three stages that can be seen from the courtyard.
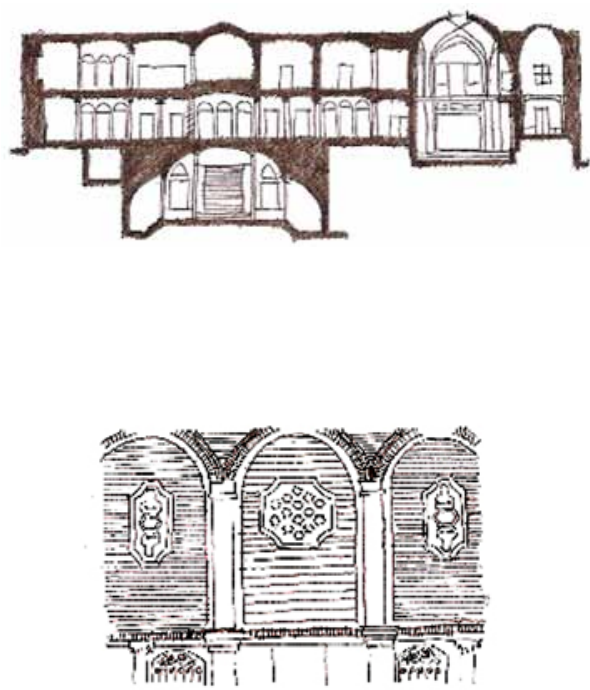

- The structural pattern of the house is formed by a rectangular courtyard. The courtyard, as the key element, integrates the plurality of components and arranges their diversity into a readable harmony. The final structure has an ordered and integrated geometry.

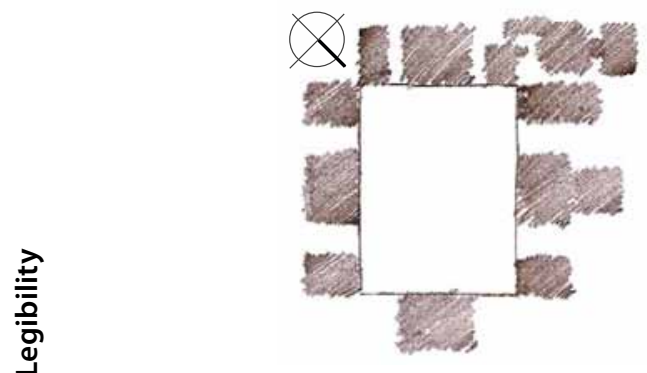

- Organized around a rectangular pattern: 1) the main elements, which are communal spaces like 'Panj-dari', 'Orosi' and 'Eivan', are located on the main axes facing to courtyard, 2) the secondary elements, which are private spaces like 'Seh-dari' and 'Bala-khaneh', are located beside the main elements, and 3 ) the service elements which are kitchen ('Matbakh'), corridors ('Dalan'), entrances, and WC, are located at the corners.
- Open spaces, semi-open spaces, and closed spaces, have dependent functions. A semi-open space usually joins a closed space and an open space. At the same time, all three types of spaces may have independent functions.
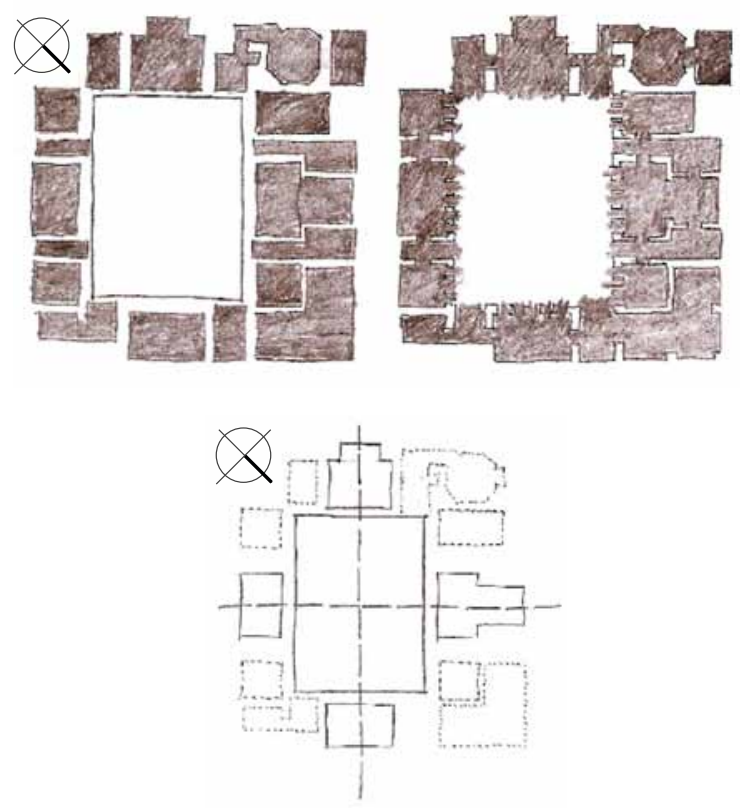
- The architecturally identified places are adaptable to different functions according to different needs during one day, or passing seasons and years.

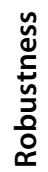

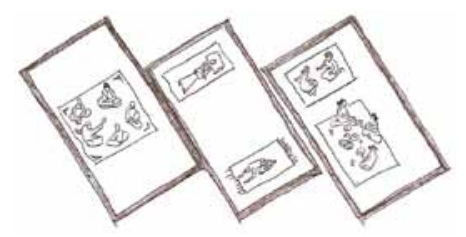

- The possibility of detaching or attaching adjacent places via small scaled joints yields a special kind of flexibility. As a result, the places have independent roles, but can work together when connected.

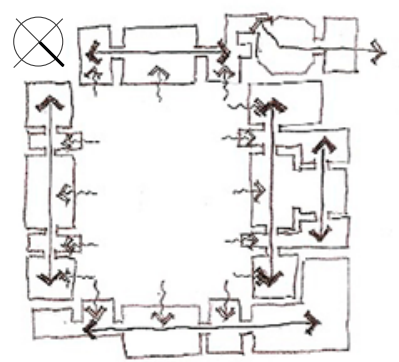

- The dimensions of the courtyard and the main spaces follow the golden proportion rule as a visual impression. This identifies the main spaces.

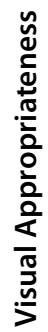

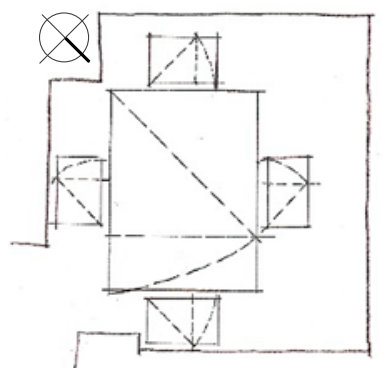

- The general proportion of facades is horizontal. The orientation of the frames of doors and windows is vertical. The composition of general horizontality of the facade and the vertical orientation of the frames produces a total visual balance.

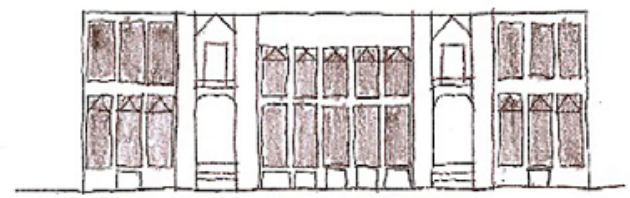

- The balanced interaction between positive and negative masses in horizontal plan (i.e., the interaction of building mass and courtyard) and in every individual façade (i.e., the interaction of opaque parts (walls) and transparent parts (windows/doors( of facade) produces visual balance.
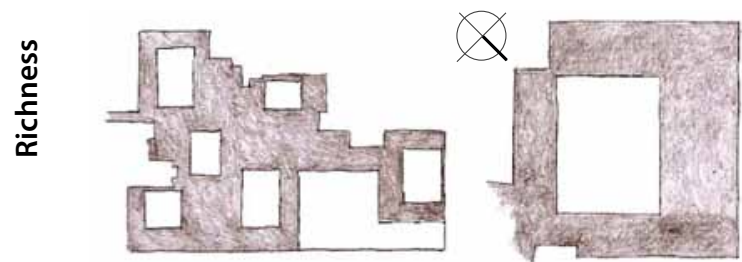

- The diversity of decorative figures of walls, ceilings, and floors specializes the quality of every individual space.

\section{Environmental appropriateness of the TPH}

\section{Providing water}

Access to water is a major problem in many areas of Persia, especially those with hot and arid climates. In traditional buildings, the problem of access to water is solved in two ways. The first method, is for when the water is available right below the building due to the presence a 'Qanat' or its sub-branches. In such cases, the building is constructed at a level below the surface of the land. In special cases, in hot and arid regions, water is provided through making two different levels of courtyard (one courtyard called 'Godal-baqcheh' situated lower than the main courtyard) or building a 'Payab', a stair leading to running water below the 
building. In these cases, the situation of the rooms around the 'Godal-baqcheh' makes access to water easier, and provides a fine view for the rooms. By providing more shade, the courtyard and 'Godal-baqcheh' also influence the adjustment of climatic conditions.

The second method is for cases in which there is no water below the building. In such cases, usually a space called 'Ab-anbar' (literally water storage) is built at the basement level, to which water is directed via channels, and is stored there. Pools ('Houz'es) at the center of the courtyard also play a similar role. ${ }^{12}$

\section{Adjusting climatic conditions}

Probably, one of the most impressive aspects of the TPH is its adaptability to environmental and climatic conditions for the benefit of the inhabitants. In Persia, there are four climatic regions, two of which, the cold, and the hot-arid climates, cover most of the country's terrain. In both of these regions, the main issue is heat isolation in order to minimize the heat exchange between the building interior and the exterior, and to delay the duration of this exchange. For this reason, there are interesting similarities between the buildings of these two climates. In order to address this issue, the materials used for construction of the building are mainly clay bricks, clay render, and fired bricks, all of which have high heat capacities which provide good heat insulation. The reduced heat transfer between the interior and the exterior, and the delay in the transfer means that the heat of the daytime is transferred into the building in the evening. Other techniques used for insulation are the use of roofs made up of two separate layers, and the use of thick walls.

The spatial organization and the overall model of the buildings are condensed and collective, so that communication with the exterior is minimized. In addition, buildings are made underground in order to take advantage of the coolness of earth in the summer, and its warmness in the winter. The urban residential fabric is also dense.

Building orientation is south-east (in hot regions), and south-west (in cold regions) in order to take full advantage of the sun's rays in the winter, and that their penetration into the building is minimized in the summer. However, differences between these two types of buildings can be observed in their roofing and the external surfaces. Roofing in the house of the hot and

\footnotetext{
12 For more information about the water supply methods in the TPH cf. Ghezelbash, Abouzia 1985; Rainer 1977.

For more information about the architectural structure of water storage ('Ab-anbar') $c f$. Pirnia 1992; Varjavand 1987.

For more information about the Persian pools ('Houz') $c f$. Daneshdust 1990.
}

arid regions is in the form of dome or vaulting, so that at all times during sunlight, parts of the roof will be in the shade. This causes a temperature difference between the parts of roof in the shade and those in sunlight, which generates a constant air movement over the roof. Conversely, in the houses of cold regions, where roofs are flat, the sun shines constantly all over the roof.

A similar phenomenon can be observed in vertical surfaces. In hot climates, the intention has been to form as many breaks, recesses, or projections as possible in the elevations in order to have shadows cast. As a result, air movement is generated, which cools the building. In some cases, the scale of these recesses or projections is so great that it leads to the formation of two level courtyards (the lower one as a 'Godal-baqcheh'). On the contrary, external building surfaces in cold climates are completely flat. Furthermore, in hot regions, external surfaces are covered by smooth and light-colored materials such as clay and straw mix or plaster rendering so that most of the rays of light are reflected back and are not absorbed by the building; while in cold climates external surfaces are textured and darker in order to absorb the maximum amount of the sun's rays. Another major difference is in the shape of windows. In hot climates windows are divided into smaller parts so that the sun's rays are diffracted and penetrate the building indirectly. Also wide horizontal and vertical bands called either 'Tabesh-band' or 'Aftab-geer' are placed above and on the sides of windows that cast shadows and prevent the direct penetration of light into the interior. In cold climates, on the other hand, windows have larger divisions and face the light. In both climates, doors and windows are usually double doors or windows, which in addition to giving symmetry to their overall shape, occupy less space when open, and also allow the passage of only one person and less transfer of heat when opening both leaves is not necessary.

At the same time, the distinctive element of the traditional Persian architecture in adapting to the environment in the country's hot regions is a structure called the 'Baad-geer'. This is a tower placed on the southern side of the house (connecting to the shaded part of the courtyard) that opens up at the suitable height towards the direction of what is called 'a good wind' ('Gol-baad'); the tower has also another opening with an independent vertical channel, parallel to the first one, on the opposite side ${ }^{13}$.

The tower is linked as a double shaft to 'Talar' and the pool room in the basement (under the 'Talar'). Wind blowing at the top will on one side force air into one shaft and will at the same time result in a suction

\footnotetext{
${ }^{13}$ For more information about wind tower ('Baad-geer') function cf. Kleiven 2003; Allard 1998.
} 
effect in the parallel shaft of the tower. In this way, cool air coming from beyond the city (gardens, farmlands, or mountains) enters 'Talar' and the cool pool room, and warm air is extracted from the opposite side. The pool room has a perforated surface on its courtyard side that blows cool air into the courtyard, passing over the courtyard's pool and plants, which having absorbed more moisture and getting refined, will then ventilate the spaces that surround the courtyard. In this way, it can be said that several components of the physical entity of the Persian House in the hot climate contribute in providing a natural cooling system ${ }^{14}$.

\section{Providing natural light}

Another issue that is being given thought in adjusting environmental conditions in housing in Persia is the method of using natural light. In the spaces of the TPH natural light enters the interior both directly and indirectly. Direct light generally enters through apertures or windows on the external skin of covered spaces that surround the courtyard.
As was explained earlier, in order to modify such a light, geometrically perforated surfaces or colored glass pieces were used. In this way, as well as providing direct light, windows also displayed the charm of the courtyard and also their own charm as beautiful objects in their own right.

However, another method of taking advantage of natural light was bringing it in through the roof. This was achieved by building certain devices ('Kolahfarangi') on the roof.

The distinctive feature between this kind of light and the former was in that because of the directness of light in the first case, it is a light that changes during the passage of the day; while because light coming from the roof was refracted and would come in from different directions, it was considered to be an even and adjusTable light. Besides providing natural light, the roof openings can affect the air circulation of internal spaces.

In a conclusion of part 2 , here in Table 2 is a categorized items which can imply responsiveness to environmental requirements in the TPH.

Table 2. Responsiveness to environmental requirements

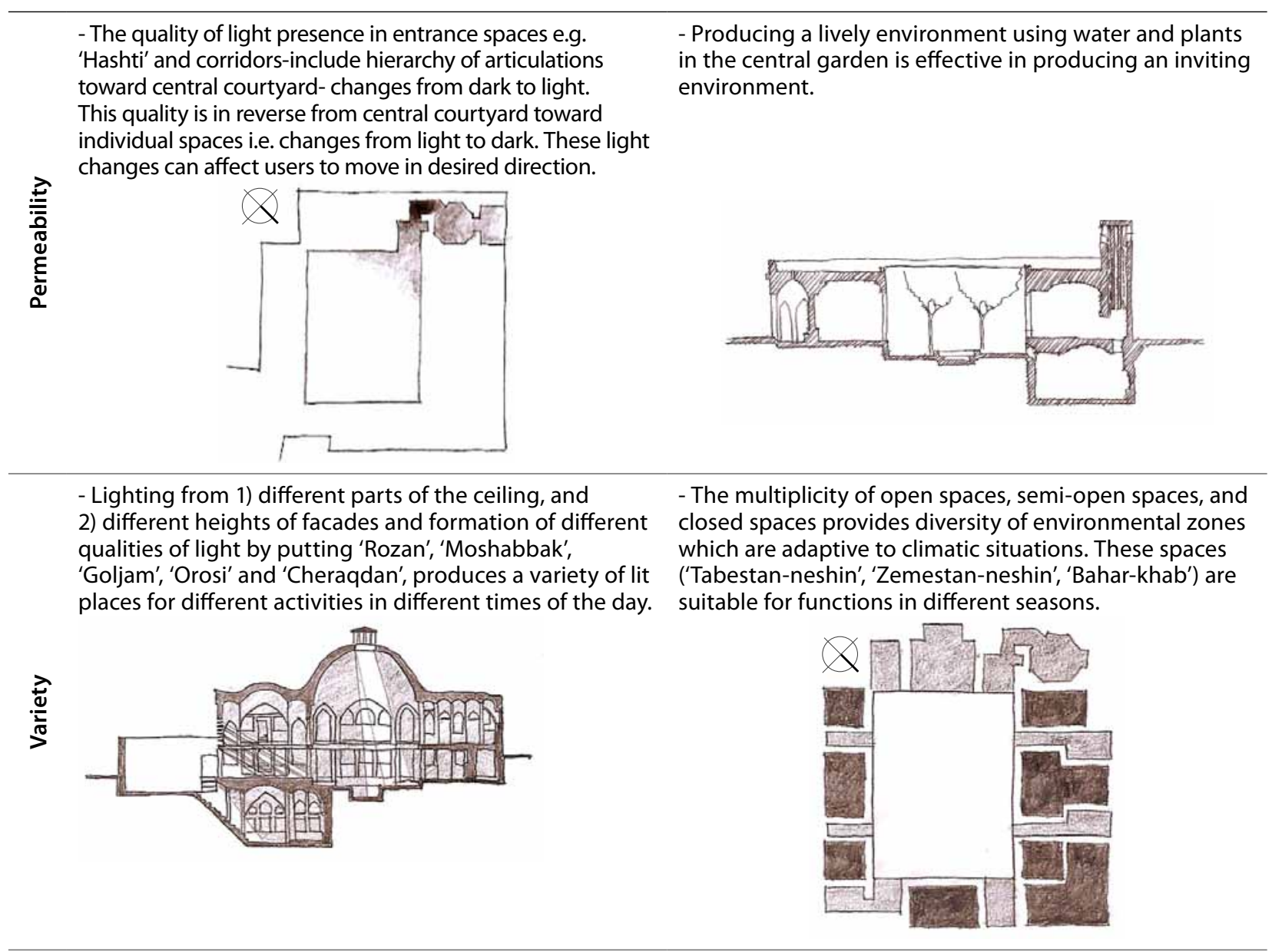
14 For more information about climatic adjustment methods in the
TPHs cf. Tavassoli 2012; Pirnia 1992; Kasmaee 1984; Ghobadian 1998. 
- The organization of the general pattern of the TPH and
its special elements, such as roofing, walls, and windows,
in accordance with environmental factors, is effective in
producing a regional identity.

- The formation of spaces which responds to climatic changes, provides the possibility of finding a comfortable place for activities in every season.

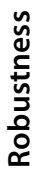

$\check{气}$ - The balanced presence of the environmental elements such as plants and water with optimum interaction with

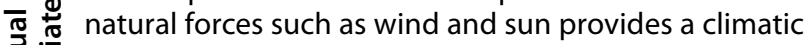
$\stackrel{5}{>}$ 응 comfort along with a charming natural view.

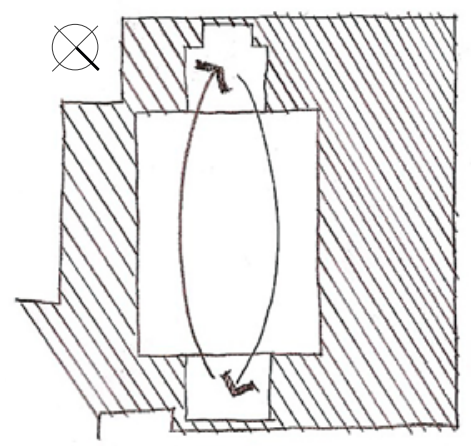

- The vertical frame proportion of the windows provides an environmental scene which presents the view of the land and the sky at the same time.

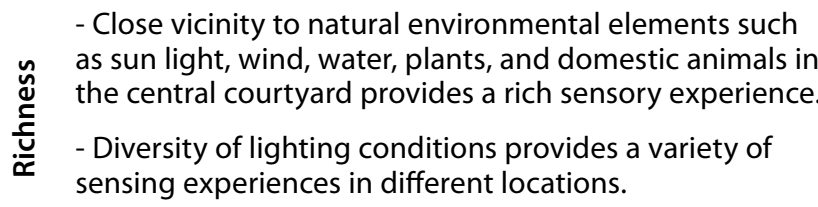

sensing experiences in different locations.
- The inward-looking organization of the building and the relative separation of the building from the urban environment provides a sense of serenity and quietude which, for private life, is considered highly desirable by many.

- Living in a space which is constructed from natural material produces a richer sensory experience.

\section{Social and cultural appropriateness of the TPH}

It seems that one of the most fundamental factor in the formation of the Persian House has been culturalsocial issues and the people's way of living. What features most of all in the form of the Persian House plays distinctive role is its inward-looking aspect. In its urban facade capacity, the Persian House has not offered much more than a presentable entry and mud walls. Contrary to its simple appearance, the interior of this modest body embraces a whole world of beauty and mystery. In addition to the cultural beliefs and climatic conditions that necessitated the hiddenness of the house, this aspect of the Persian House can be attributed to the characteristic of a people who had a simple appearance, but also a sincere and warm soul. Besides, the culture of the Persians is an introverted culture in itself; something that can be discerned from their social structure.
The structure of the town's quarters was also influenced by ethnic-religious relationships. As a result of ethnic-religious relationship, a kind of public oneness would exists between the members of a quarter that originated in the strong sense of belonging of people to their neighborhood. This was a kind of oneness that at the same time could fit poverty and affluence within it in a way that sometimes the poorest people would live in a house next to richest. Considering the inward-looking aspect of the houses and their simple appearance, this subject does not present a problem and "people's dignity was safeguarded". At the same time, the poor would benefit from being neighbors to the rich, since "a Muslim who finds it possible to go to sleep when his neighbor is hungry, is not a Muslim at all"15; This combination of the

\footnotetext{
15 Referring to a hadith mentioned by Prophet Muhammad (pbuh). In hadiths, up to forty houses distance can be assumed as a house neighbor, what can be called a neighborhood.
} 
houses of the poor and the rich in the neighborhoods was an indicative of the spiritual unity of the community.

The crystallization of a social system based on the ethnic-religious structure and the introverted culture can be observed as a strong spatial hierarchy from the scale of the city to the home: from the 'Bazaar' as the most public, active, and vibrant space to the arcade ('Gozar'), then to the street ('Koocheh'), then to the narrow street ('Pas-koocheh'), then the neighborhood alleyway ('Darband'), then to the entrance space ('Dargah'), then from the entry to the vestibule ('Hashti'), then to the corridor ('Dalan'), and finally into the courtyard ('Hayat'), that is the heart of the Persian House.

As the connection between the interior and the exterior, the entrance space finds a special physical expression here. The entrance to the Persian house is not just a door that separates the inside from the outside, but is a covered space that also contains seats on both sides ('Peer-neshin') for waiting or brief encounters; and above the entrance is a Tablet containing a sacred script welcoming the visitor. A point that is felt at such an elaborate entrance indicates a religious belief: the distinction between those who can be privy and those who cannot. Two knockers, one shaped as a ring, and another as a hammer or a fist feature on the door, one fixed on one leaf, and the other on the second leaf. The softer sound of the ring signals the arrival of one who is privy, and the heavier sound of the other signals the contrary.

The formation of the spatial hierarchy of the house from entrance gate to the courtyard not only speaks of the religious beliefs and culture of the family, but also contains a number of psychological points: the space in front of the entrance is a place for a pause before entering the house, the low door makes the visitor bough a little, the shift of direction of the axis of the 'Dalan' after the entrance vestibule ('Hashti') prevents a view into the private parts of the house, and the obscurity of the route, which is intensified by the dimness of the light, as well as the sequence of the spaces of entrance- vestibule- corridor that have distinct architectural definitions that evoke pause and movement, disengage the visitor's mind from the outside and prepare him for entering into the realm of the family.

However, the TPH must be considered to be the physical expression of the institution of the Persian family. Similar to the members of a family who gather around to eat, the components of the house surround a courtyard garden (symbolizing the paradise of the family). The large size of the family in the structure of the older Persian family necessitated the provision of a variety of collective spaces (for the gathering of the whole or part of the extended family) or for individuals (privacy and retreat). As a result spaces of different sizes would be formed. If we also consider climatic factors, we can see that spatial variety can be found not only in the sizes of spaces, but also in the degree of their openness or closeness to the outside (open spaces, semi-open spaces, closed spaces). This is important because the culture of the Persian family required that first of all a spatial distinction should exist on the privy and non-privy basis, and that secondly a large part of the members of the family, that is the women should spend most of their time in the house. In addition, the presence of the family members in the house during the day was considerable in traditional life and so it necessitates providing different spaces.

The sum total of these issues could result in a house having two or more courtyards depending on the degree of privacy required. This would result in forming a private courtyard ('Andarooni') for the principal residents and another ('Beerooni') for guests (Fig. 6). Also the number of courtyards could increase due to the affluence and life style of the families; including the groom's courtyard (for the residence of the groom), the 'Narenjestan' for the family's winter use, and other similar courtyards. In this way, a 'residential complex' that had a suitable degree of spatial variety would form for a large number of residents that made taking advantage of nature and contact with others at different levels of collectiveness possible. Generally, it can be said that each space would find its suitable place in the overall organization depending on the degree of privacy required, and that the geometry that governed the totality of the building and its components was representative of the special character of each space.

In a conclusion of part 3 , here in Table 3 is a categorized items which can imply responsiveness to socialcultural requirements in the TPH.

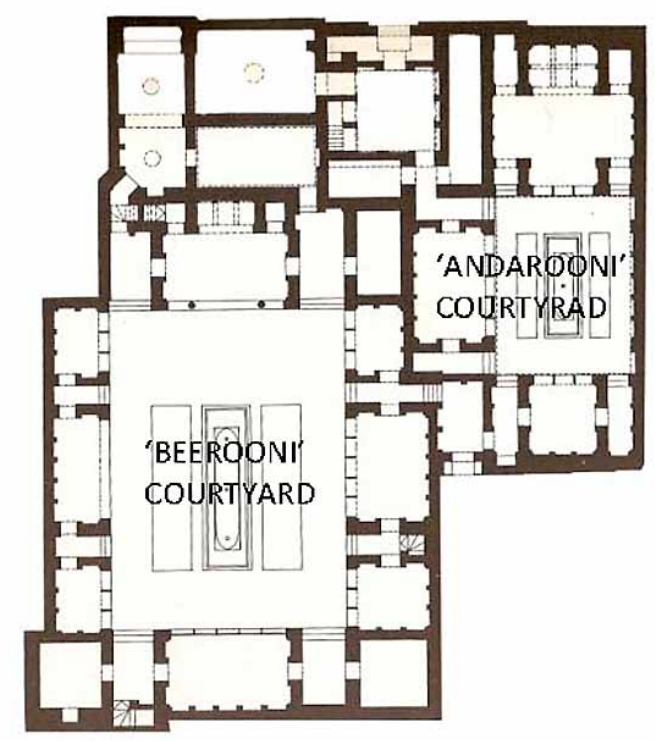

Fig. 6. A plan of a TPH complex with two different 'Andarooni' and 'Beerooni' courtyards in Gazorgah neighborhood in Yazd (Ghezelbash, Abouzia 1985: 38) 
Table 3. Responsiveness to social-cultural requirements

- Spaces are inviting according to their communal role. The accessibility of every space is defined by the extent of its communality, so the building organization affects users' route finding according to their relationship to the family.

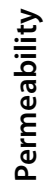

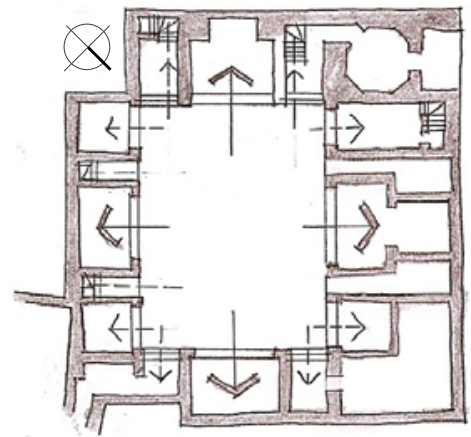

- The diversity of spaces provides choices for different private and public behavioral patterns.

$\frac{2}{\sqrt{5}}$

- The entrance place is embedded in the urban location in a way that follows the hierarchy of the urban routes from public street to semi-private, and then to a private alley. This can sustain the ability of route finding.

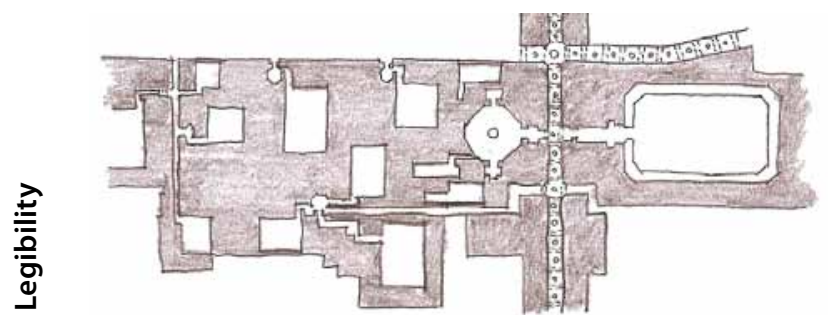

- The inward-looking organization of the house implies the private function of the building.

- The visibility and the clarity of patterns in the external part of the entrance gate, and its contrast to the ambiguity of the structure of the internal entrance corridors (due to their swirling and darkness) provides a hierarchical structure from public to private areas.

- In the TPH, there is a compatibility between spatial pattern and the pattern of family life.

- The diversity and multiplicity of places makes the building responsive to the changes in family size during the occupants' life time.

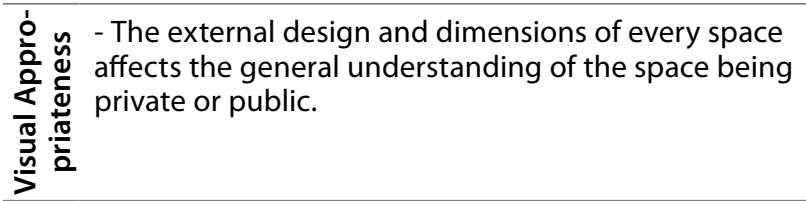

- A cultural avoidance of ostentation and lavish dissipation $\frac{\tilde{y}}{\underline{\underline{c}}}$ often motivates the occupants to see beauty in simplicity.
- The design and decoration of the entrance gate presents the external identity of the house.

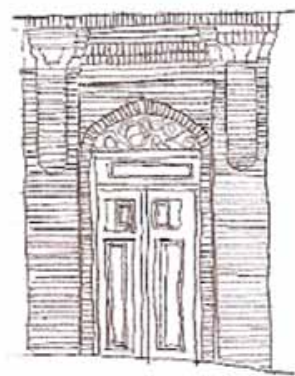

- The quality of hierarchical organization of internal spaces shows the degree of privacy or publicity of every space. The quantity of this hierarchy (in terms of complexity or the number of hierarchical levels) shows the owners' social ranking.

- As the spaces are not designed for a particular function, they can accommodate different types of activity. As women spend most of their time in internal spaces, the diversity and adaptability of the spaces provides the possibility of producing different handicrafts and indoor arts and crafts.

- The number of public areas is one of the criteria which shows the extent of family's social communication.

- The inward-looking organization separates the house from the public in an urban area and helps in providing a calm environment suitable for rich experiences needed for a private family life.

- Safety, privacy, and familiarity of home interiors, as well as the beauty of the middle courtyard, make the house a memorable place. It strengthens the sense of belonging in the residents. 


\section{Conclusions}

Ancient Persians considered the world to be composed of the four elements of water, wind, earth, and fire. As a result of this belief, the TPH can be considered to be a world that is organized to suit the spirits and bodies of its residents using water, earth, wind, and the sun. The TPH is also considered an entity whose architectural spaces and changing functions throughout the day made it not only an 'ingenious architecture' but also, according to the analysis of this paper, a 'responsive environment'.

The analysis of this paper shows that the responsiveness criteria, i.e., 'permeability', 'variety', 'legibility', 'robustness', 'visual appropriateness', 'richness', and 'personalization', are obtained from functional-constructional, environmental, and social-cultural viewpoints in the TPH (Fig. 7).

It seems that reaching such criteria has been a result of intelligent application of fundamental structural principles of the TPH, such as inward-looking pattern, spatial hierarchy, and spatial diversity. The conscious application of these key principles provides an integrated basis for addressing functional, constructional, environmental, and social-cultural necessities and so it responds to issues such as human scale, climatic situation, light, view, townscape, family relationships, and life style, all together through common solutions.

It can be said that the responsiveness of the $\mathrm{TPH}$ is the result of the efforts of several generations of Persian architects, and current and future Persian architecture models can be improved through recreation of the principles used by those generations. In other words, responsive criteria used in the past, in combination with creative and contemporary looks and interpretations, have the potential to form new and rich experiences.

\section{References}

Abolghasemi, L. 1987. The norm of finding shape in Iran's architecture, in M. Y. Kiani (Ed.). Iran Architecture in Islamic Period. Tehran: Jahad-e-Daneshgahi Publications, 358-379.

Allard, F. 1998. Natural ventilation in buildings. London: James \& James.

Ardalan, N.; Bakhtiar, L. 1973. The sense of unity. Chicago: University of Chicago Press.

Bentley, I.; Alcock, A.; Murrain, P.; McGlynn, S.; Smith, G. 1985. Responsive environments. London: The Architectural Press.

Bozorgmehri, Z. 1987. The arches in the Islamic architecture, in M. Y. Kiani (Ed.). Iran Architecture in the Islamic Period. Tehran: Jahad-e-Daneshgahi Publications, 380-396.

Daneshdust, Y. 1990. Once there was a town called Tabas. Tehran: Cultural Heritage Organization \& Soroush Press.

Documentation and Research Center, Faculty of Architecture and Urban Planning, Shahid Beheshti University. 1996.
Ganjname. Vol. 1. Mansions of Kashan. Tehran: Iran Cultural Heritage Organization.

Ghazbanpoor, J. 2001. Iranian house. Tehran: Tis Publication.

Ghezelbash, M.; Abouzia, F. 1985. Alphabets of Yazd traditional house. Tehran: Program and Budjet Organization.

Ghobadian, V. 1998. Climatic study of Iran's traditional buildings. Tehran: University of Tehran Publication.

Kasmaee, M. 1984. Climate and architecture. Tehran: Iran's House Building Cooperation.

Kiani, M. Y. 2000. History of Iran architecture in Islamic period. Tehran: Studying and Organizing Humanities Books Organization (SAMT).

Kleiven, T. 2003. Natural ventilation in buildings: architectural concepts, consequences and possibilities. Norway: Institutt for byggekunst, historie og teknologi.

Memarian, Gh. H. 1996. Acquaintance with Iranian residential architecture: looking inward type. Tehran: Iran University of Science and Technology.

Pirnia, M. K. 1991. Dome in Iran architecture, in Z. Bozorgmehri (Ed.), Asar Journal (20): 5-139.

Pirnia, M. K. 1992. An acquaintance with Islamic architecture of Iran, in Gh. H. Memarian (Ed.). Tehran: Iran University of Science and Technology Press.

Pirnia, M. K. 1994. Chafdha and Taghha, in Z. Bozorgmehri (Ed.), Asar Journal 24: 4-45.

Pope, A. 1976. Introducing Persian architecture. Japan: Asia Institute Books.

Rainer, R. 1977. Traditional building in Iran. Graz: Akademische Druck- u. Verlagsanstalt.

Tavassoli, M. 2012. Urban and architectural structure in Iran's warm and hot climate. Tehran: University of Tehran Publications.

Varjavand, P. 1987. 'Ab-anbar's, in M. Y. Kiani (Ed.). Iran architecture in the Islamic period. Tehran: Jahad-e-Daneshgahi Publications, 154-164.

Yarshater, E. 1996. Encyclopedia Iranica. New York: Encyclopedia Iranica Foundation.

\section{Appendix: the glossary of terms}

Ab-anbar: Water storage. A space which is built at the basement level. There are channels which direct water to it.

Aftab-geer: Wide horizontal and vertical bands which are placed above and on sides of windows that cast shadows.

Andarooni: Private courtyard and its component for the principal residents.

Baad-geer: Wind tower which is usually used in warm regions. It is a tower that directs cool wind into the closed space and remove warm air out.

Bahar-khab: A kind of roof which is used for sleeping at night in warm seasons.

Bala-khaneh Gooshvar: Corner upper room which is usually used for retreat and privacy. 'Goosh' means corner.

Bala-khaneh: Upper level rooms. 
Bazaar: Central city market place which has linear organization.

Beerooni: Public courtyard and its components usually used for guests.

Cheraqdan: A kind of hole in the wall that is covered with glass and is open to both interior and exterior. It is the special place for oil-burning lamps.

Dalan: Corridors.

Darband: Neighborhood alleyway.

Dargah: Entrance gate.

Dastgah-e-moosighi: Persian music structure.

Eeivan: A covered space which is open in the side connecting to the courtyard.

Godal-baqcheh: A yard situated lower than the main courtyard.

Gol-baad: Suitable wind.

Goljam: Glass slices formed with narrow strip of plaster used as a decoration on the upper part of the door.

Gol-o-botte: Flower and bushes in traditional carpet pattern.

Gozar: Arcade.

Hashti: Vestibule. Primary entrance space.

Hayat: Courtyard. Generally is called to internal open spaces which surrounded by walls.

Houz: Pool.

Houz-khaneh: Pool room located in lower level i.e. basement.

Khesht: Clay brick.

Kolah-farangi: Certain devices on the roof for letting natural light into the space.

Koocheh: Street.

Mahtabi: A kind of roof which is used for sleeping in warm seasons.

Mard-gard: The semi-open corridors that connects the open space to closed space by a swirl. 'Mard' means man and 'Gard' means swirl.

Matbakh: Kitchen.

Moshabbak: A mesh surface usually used for providing semi-open view for windows.

Narenjestan: Special courtyard which can be covered by tent for the family's winter use. Usually there has been planted orange, lemon or citrus trees in this yard. The term literally means citrus fruit garden.

Orosi: Literally it is a kind of vertical window that covers ground to ceiling of the space. It is also used for the name of the main room which has vertical sash perforated window with colored glass pieces in the perforations. The room is usually cross-shaped in the horizontal section.

Ozan-e-aroozi: Different defined rhythm structures in Persian poem.
Paeen-khaneh: The part of house located in the ground floor level.

Panj-dari: The main room which has an aperture with five divisions.

Pas-koocheh: Narrow street, back street.

Pastoo: Storage room at the rear part of the main rooms.

Payab: A stair leading to running water below the building.

Peer-neshin: Seats on the sides of the external part of the entrance gate.

Peimoon: A kind of scale defining system. It was a means at the disposal of the architect by which the dimensions, proportions and interrelationships in a building would be organized. There was three main 'Peimoon' system in traditional houses which are called: big 'Peimoon', small 'Peimoon' and sub-'Peimoon'.

Qanat: It is a kind of method for providing water from ground depth in hot and arid climate. It is consisted of a series of well-like vertical shafts that are connected horizontally.

Rozan: The window which is usually located above the door.

Sandoq-khaneh: Storage room at the rear part of the main rooms.

Sardab: Pool room located in lower level i.e. basement.

Seh-dari: The secondary room which has an aperture with three divisions.

Shah-neshin: The recess at the back of the 'Orosi' or 'Panj-dari' room. The term means king's seat.

Shekam-darideh: It is a kind of room (usually 'Orosi' room) which looks like a cross shape.

Sofeh: A raised area beside one of the sides of the courtyard usually used for siting.

Tabesh-band: Wide horizontal and vertical bands which are placed above and on sides of windows that cast shadows.

Tabestan-neshin: Southern part on the house organization which cast shadow and is suitable for the summer life.

Takht-gah: Covered space which is open to courtyard providing access to closed spaces.

Talar: Room attached to the wind tower in the southern part of courtyard. It is similar to an 'Eivan' which is open to the courtyard side and at the back of which is the wind tower.

Tenabi: A big room at the rear side of the 'Talar'. It is usually gets light by roof.

Zemestan-neshin: Northern part on the house organization which gets direct sun shining and is suitable for the winter life. 


\section{MARYAM GHARAVI ALKHANSARI}

School of Architecture, College of Fine Arts, University of Tehran, Enghelab Avenue, 14174-66191 Tehran-Iran. E-mail: mgharavi@ut.ac.ir

Assistant Professor of Architecture at the Faculty of Architecture, University College of Fine Arts, University of Tehran. She received her doctorate in Architecture from University of Tehran. Her PhD is about flexibility in architecture and she has continued her researches and published several papers in this area. She has taught history of architecture and architectural design courses in recent years. Her areas of interest and research include history of architecture and architectural flexibility. 